\title{
Team Structure and Culture Are Associated With Lower Burnout in Primary Care
}

\author{
Rachel Willard-Grace, MPH, Danielle Hessler, PhD, MS, Elizabeth Rogers, MD, \\ Kate Dubé, BA, Thomas Bodenheimer, MD, MPH, and Kevin Grumbach, MD
}

Purpose: Burnout is a threat to the primary care workforce. We investigated the relationship between team structure, team culture, and emotional exhaustion of clinicians and staff in primary care practices.

Methods: We surveyed 231 clinicians and 280 staff members of 10 public and 6 university-run primary care clinics in San Francisco in 2012. Predictor variables included team structure, such as working in a tight teamlet, and perception of team culture. The outcome variable was the Maslach emotional exhaustion scale. Generalized estimation equation models were used to account for clustering at the clinic level.

Results: Working in a tight team structure and perceptions of a greater team culture were associated with less clinician exhaustion. Team structure and team culture interacted to predict exhaustion: among clinicians reporting low team culture, team structure seemed to have little effect on exhaustion, whereas among clinicians reporting high team culture, tighter team structure was associated with less exhaustion. Greater team culture was associated with less exhaustion among staff. However, unlike for clinicians, team structure failed to predict exhaustion among staff.

Conclusions: Fostering team culture may be an important strategy to protect against exhaustion in primary care and enhance the benefit of tight team structures. (J Am Board Fam Med 2014;27: 229-238.)

Keywords: Burnout, Organizational Culture, Patient Care Team, Primary Health Care

Burnout is a threat to the primary care workforce. Staff and clinicians in primary care report high levels of emotional exhaustion, ${ }^{1}$ with primary care physicians evincing some of the highest levels of burnout among physician specialties. In a recent survey, more than $50 \%$ of primary care clinicians

This article was externally peer reviewed.

Submitted 24 July 2013; revised 21 November 2013; accepted 27 November 2013.

From the Department of Family and Community Medicine, University of California, San Francisco (RW-G, DH, $\mathrm{KD}, \mathrm{TB}, \mathrm{KG})$, the Center for Excellence in Primary Care (RW-G, DH, ER, KD, TB, KG), and Divisions of General Internal Medicine and Pediatrics (ER), University of California, San Francisco.

Funding: This work was supported by funding from the California Medicaid Waiver Delivery System Reform Incentive Program to San Francisco General Hospital and the University of California, San Francisco Medical Center.

Conflict of interest: none declared.

Corresponding author: Rachel Willard-Grace, MPH, Department of Family and Community Medicine, University of California, San Francisco, 1001 Potrero Ave, Ward 83, San Francisco, CA 94114 (E-mail: willardr@fcm.ucsf.edu). reported symptoms of burnout, compared with $28 \%$ of the general employed population. ${ }^{2}$

Characterized by low professional efficacy, high exhaustion, and high cynicism, ${ }^{3}$ burnout threatens recruitment and retention of primary care clinicians. Apprehensions about the stresses of primary care practice may contribute to the decreasing numbers of medical graduates and physician assistant graduates choosing careers in family medicine or general internal medicine. ${ }^{4-9}$ Clinicians experiencing burnout are more likely to leave medicine entirely. ${ }^{10,11}$ Although risk factors for and effects of burnout among clinical support staff have been less studied, these members of the primary care team face many of the same challenges associated with clinician dissatisfaction, such as a hurried and chaotic work pace and lack of control over their work environment. ${ }^{11}$

The consequences of burnout are pernicious and far reaching. Clinician burnout and corresponding professional dissatisfaction have been associated with medical errors, ${ }^{12-14}$ reduced quality of medical 
care,${ }^{15-17}$ poor communication with patients, ${ }^{17}$ longer recovery time following hospitalization, ${ }^{18}$ poor adherence of patients to care plans, ${ }^{19}$ lower patient satisfaction, ${ }^{18,20}$ and a reluctance to take on new patients insured by Medicaid or Medicare. ${ }^{15} \mathrm{In}$ the face of these challenges, clinician well-being has been proposed as a new quality indicator. ${ }^{21}$

Team-based care may serve as an antidote to the overwhelming demands of primary care. ${ }^{22,23}$ Case studies of high-performing practices frequently cite tight team structures as instrumental to practice transformation and the improvement of patient care. ${ }^{24,25}$ Effective team functioning in health care is associated with greater career satisfaction among clinicians as well as improved quality of care and greater patient satisfaction. ${ }^{24,26}$

We investigated the relationship between team structure, team functioning, and emotional exhaustion of clinicians and staff in primary care practices. Our hypotheses were 3-fold. First, we hypothesized that a tight team structure, such as a "teamlet" model in which a clinician works with the same medical assistant or other support staff on a consistent basis, ${ }^{23}$ would be protective against exhaustion, the central and most obvious symptom of burnout. ${ }^{3}$ Second, we hypothesized that team culture-a sense of effective team functioning among clinicians and staff-would be associated with lower exhaustion. Finally, consistent with the conceptual model of teamwork developed by Hack$\operatorname{man}^{27}$ positing structure as an enabler of team performance, we hypothesized that the relationship between team structure and exhaustion would depend on team culture within the clinic.

\section{Methods}

We conducted a cross-sectional survey of clinicians and staff in primary care practices using a selfadministered questionnaire conducted in waves across the study sites between February and May 2012. The study included 10 of the 11 clinics providing comprehensive primary care services in a county-administered health system (one clinic declined to participate) and all 6 comprehensive primary care practices in a university-administered health system, with an annual visit volume of 264,000 in 2011. The county-administered system serves primarily publicly insured (64\%) and uninsured $(36 \%)$ populations, whereas the university system serves primarily patients with commercial insurance (66\%) and Medicare (23\%). Two of the practices in each system were residency program teaching clinics, and all practices were located in San Francisco, California. None of the participating practices had applied for formal recognition as a patient-centered medical home at the time of the survey. All staff and clinicians (physicians, nurse practitioners, and physician assistants) at the clinics were eligible for the study.

\section{Measures}

Survey measures examined team structure, team culture, exhaustion, and respondent characteristics. Team structure may encompass several elements, such as the different professional disciplines and role definitions among team members. ${ }^{27} \mathrm{We}$ focused exclusively on one important domain of team structure: the consistency with which clinicians are paired with the same clinical assistants, which has been suggested as an ingredient of high-performing primary care. ${ }^{23}$ We measured team structure using an item developed by the study team. For clinicians, the item asked, "Which of the following best describes your team model at your clinic?" Response categories were (1) I almost always work with the same medical assistant, (2) I almost always work with a small group of medical assistants, or (3) I rarely work with the same medical assistant or small group of medical assistants. For staff, the item asked, "Do you have a consistent working relationship with one provider or a small team of providers (a small subset of providers in your clinic, such as a pod or a teamlet)?" Response categories were yes or no.

Research has identified a number of domains that make up "team culture," including the quality of task-related interactions (eg, communication, participation, effort) and the quality of social interactions (eg, social support, respect, shared objectives). ${ }^{27,28}$ After reviewing the literature, we did not find a concise, validated team culture measure for primary care that adequately captured the desired components. We therefore developed an 8-item measure by adapting items from the Team Climate Survey $^{29}$ and the inventory of adaptive reserve. ${ }^{30}$ Each item was rated on a 10-point Likert scale, ranging from strongly disagree (1) to strongly agree (10). After reverse-coding 2 items, we tested the internal validity of the team culture scale by conducting a principal components factor analysis with promax rotation for these 8 items. Of the 8 items, 


\begin{tabular}{|c|c|c|c|c|c|}
\hline Item & Mean & Median & Standard Deviation & Range & Factor Loading \\
\hline $\begin{array}{l}\text { The group of staff and providers I work with } \\
\text { most regularly work well together as a } \\
\text { team. }\end{array}$ & 7.09 & 7.00 & 2.35 & $1-10$ & 0.80 \\
\hline $\begin{array}{l}\text { My most important task in clinic is to manage } \\
\text { patient flow.* }\end{array}$ & 6.52 & 7.00 & 2.71 & $1-10$ & 0.20 \\
\hline $\begin{array}{l}\text { We have a "we are in it together" attitude at } \\
\text { my clinic. }\end{array}$ & 6.42 & 7.00 & 2.60 & $1-10$ & 0.87 \\
\hline $\begin{array}{l}\text { I feel unprepared for many of the tasks that I } \\
\text { am asked to do every day. }{ }^{\dagger \neq}\end{array}$ & 7.76 & 9.00 & 2.47 & $1-10$ & 0.35 \\
\hline $\begin{array}{l}\text { My professional skills are used to the fullest at } \\
\text { my clinic. }\end{array}$ & 6.39 & 7.00 & 2.96 & $1-10$ & 0.64 \\
\hline It is hard to get things to change in my clinic. ${ }^{\dagger}$ & 4.77 & 5.00 & 2.56 & $1-10$ & 0.60 \\
\hline $\begin{array}{l}\text { I can rely on other people at my clinic to do } \\
\text { their jobs well. }\end{array}$ & 6.66 & 7.00 & 2.25 & $1-10$ & 0.72 \\
\hline $\begin{array}{l}\text { We regularly take time to consider ways to } \\
\text { improve how we do things at my clinic. }\end{array}$ & 6.87 & 7.00 & 2.47 & $1-10$ & 0.69 \\
\hline
\end{tabular}

*This item was removed from the final scale.

${ }^{\dagger}$ These items were reverse-coded to develop a composite score. The results presented here are reverse-coded.

${ }^{\ddagger}$ The factor loading score for this item is low, but removal of this item did not improve the Cronbach $\alpha$, and it was retained in the final scale.

7 had factor loading scores $>0.35$ and were included in the final scale; the item "my most important task in clinic is to manage patient flow" had a low factor loading (0.20) and was excluded (Table 1). The final 7-item team culture scale had a Cronbach $\alpha$ of 0.80 . Removal of the item with a loading score of 0.35 ("I feel unprepared for many of the tasks that I am asked to do every day") did not improve the Cronbach $\alpha$, and this item was retained in the scale. The team culture scale score was computed as the mean of the 7 scale items; a higher score indicates greater team culture.

We measured exhaustion, the most obvious symptom of burnout, using the validated 5-item Emotional Exhaustion scale from the General Survey version of the Maslach Burnout Inventory (Cronbach $\alpha=0.92$ in our sample). ${ }^{31}$ The Emotional Exhaustion scale produces a mean score ranging from 0 to 6 , where 6 is the highest level of exhaustion; a score of 3.2 or higher ( $\geq 16$ on the sum score) is classified as high exhaustion.

We assessed respondent characteristics using additional questions about issues such as hours or shifts worked per week (staff: $\leq 20$ or $>20$ hours per week, clinicians: $1-2,3-5$, or $\geq 6$ half-days per week); tenure $(<1,1-5$, or $>5$ years); and system (county or university). For clinicians, we categorized respondents as resident physicians, nurse practitioners/physician assistants, or attending physicians. For staff, we grouped respondents into 2 categories to differentiate those working in direct patient care roles alongside clinicians from those working in other roles, using the question, "Do you room patients or take vitals?" From health system administrative data, we identified when each clinic first implemented its current electronic health record (EHR), hypothesizing that burnout might increase during EHR implementation (not in transition or in transition [ \pm 6 months to EHR go-live date]).

\section{Survey Administration}

The survey was offered in both web-based and paper form, based on the preferences of the clinic directors. Study personnel administered paper surveys during staff meetings. Clinicians and staff receiving web-based surveys were sent an initial invitation via $\mathrm{E}$-mail and up to 3 additional reminders by E-mail. Medical directors and clinic administrators were advised about the response rate for their site and asked to encourage staff and clinicians to respond. Respondents to the survey were entered in a raffle for $\$ 25$ gift cards.

\section{Data Analysis}

Data analysis was conducted using SPSS version 20 (SPSS Inc/IBM, Chicago, IL). We examined predictors of exhaustion using generalized estimating equation (GEE) models to account for clustering by clinics. Models were examined in stepwise fash- 
ion. Model 1 included only individual GEE models with only one predictor included at a time to examine bivariate relationships between team structure, team culture, respondent characteristics, and exhaustion scales. Models 2 to 4 were multivariate GEE models that included all participant characteristics as covariates and sequential addition of the 2 main predictor variables. Model 2 added team structure. Model 3 added team culture in addition to team structure. Model 4 included an interaction term for team structure and team culture. Analyses were conducted separately for clinicians and staff. Quasi-likelihood under the independence model criterion was calculated as a measure of goodness of fit for each model. The independence model criterion compares fit across GEE models (model selection), where a smaller model fit statistic relative to another model statistic indicates greater fit. There was a concern that residents could skew the results because of their unique experiences as clinicians in training, so we conducted a sensitivity analysis excluding this group.

The protocol was approved by the University of California, San Francisco, Committee on Human Research (11-08048). All individual-level responses were kept confidential. Medical directors and clinic administrators were provided with results aggregated at the level of their own clinic, along with results for all clinics in their system combined for comparison.

\section{Results}

Of 420 eligible clinicians, 231 (55\%) responded; 280 of 428 eligible staff $(65 \%)$ responded. Clinicians and staff of teaching clinics were less likely to respond to the survey than those at nonteaching clinics, and resident clinicians were less likely to respond than nonresidents. Most clinicians (83\%) worked part time, whereas the majority of staff worked full-time (Table 2). More than a third of clinicians responding to the survey were residents (37\%), 13\% were nurse practitioners or physician assistants, and half (50\%) were attending physicians. Just over half of respondent staff (56\%) played clinical support roles involving rooming patients or taking vital signs. Most staff (61\%) reported working in a consistent team. A few clinicians $(10 \%)$ reported rarely working with the same team members; most worked with the same group of medical assistants in a team (72\%), and almost 1
Table 2. Clinician and Staff Characteristics

\begin{tabular}{|c|c|c|}
\hline Characteristics & $\begin{array}{l}\text { Clinicians } \\
(\mathrm{n}=231)\end{array}$ & $\begin{array}{c}\text { Staff } \\
(\mathrm{n}=280)\end{array}$ \\
\hline \multicolumn{3}{|l|}{$\begin{array}{l}\text { Half days of patient care per } \\
\text { week }\end{array}$} \\
\hline $1-2$ & $116(50)$ & - \\
\hline $3-5$ & $75(33)$ & - \\
\hline$\geq 6$ & $40(17)$ & - \\
\hline \multicolumn{3}{|l|}{ Work hours per week } \\
\hline$<20$ & - & $28(9)$ \\
\hline$\geq 20$ & - & $252(91)$ \\
\hline \multicolumn{3}{|l|}{ Tenure (years) } \\
\hline$<1$ & $38(17)$ & $61(22)$ \\
\hline $1-5$ & $99(43)$ & $101(36)$ \\
\hline$\geq 5$ & $94(41)$ & $118(42)$ \\
\hline \multicolumn{3}{|l|}{ System } \\
\hline Public & $138(60)$ & $183(65)$ \\
\hline University & $93(40)$ & $97(35)$ \\
\hline \multicolumn{3}{|l|}{ EHR in transition ( \pm 6 months) } \\
\hline No & $213(92)$ & $248(89)$ \\
\hline Yes & $18(8)$ & $32(11)$ \\
\hline \multicolumn{3}{|l|}{ Clinician type } \\
\hline Attending physician & $115(50)$ & - \\
\hline $\begin{array}{l}\text { Nurse practitioner/physician } \\
\text { assistant }\end{array}$ & $31(13)$ & - \\
\hline Resident & $85(37)$ & - \\
\hline \multicolumn{3}{|l|}{ Direct role in patient care } \\
\hline No & - & $123(44)$ \\
\hline Yes & - & $157(56)$ \\
\hline \multicolumn{3}{|l|}{ Staff team structure } \\
\hline No team & - & $104(39)$ \\
\hline Team or teamlet & - & $162(61)$ \\
\hline \multicolumn{3}{|l|}{ Clinician team structure } \\
\hline No team & $22(10)$ & - \\
\hline Team & $164(72)$ & - \\
\hline Teamlet & $42(18)$ & - \\
\hline Team culture, mean (SD) & $6.17(1.62)$ & $6.90(1.65)$ \\
\hline \multicolumn{3}{|l|}{ MBI emotional exhaustion } \\
\hline Exhaustion score, mean (SD) & $3.43(1.42)$ & $2.81(1.66)$ \\
\hline Low exhaustion & $24(11)$ & $64(24)$ \\
\hline Moderate exhaustion & $63(29)$ & $89(33)$ \\
\hline High exhaustion & $129(60)$ & $117(43)$ \\
\hline
\end{tabular}

Data are $\mathrm{n}(\%)$ unless otherwise indicated.

EHR, electronic health record; MBI, Maslach Burnout Inventory; SD, standard deviation.

in $5(18 \%)$ consistently worked with the same medical assistant in a teamlet model.

The mean team culture rating among staff (6.90) was somewhat higher than that among clinicians (6.17). More than half of clinicians $(60 \%)$ and $43 \%$ of staff reported high levels of emotional exhaustion. Resident physicians reported the highest prevalence 
of exhaustion, with $69 \%$ of residents reporting high exhaustion (data not shown).

In bivariate GEE models, clinician exhaustion was positively associated with the number of half days worked, being in transition to an EHR, and being a resident (Table 3). Being in a tighter team structure and reporting a greater team culture were associated with less clinician exhaustion. For staff, working full time, having longer tenure, and being in transition to an EHR were associated with more exhaustion, whereas a greater team culture was associated with less exhaustion (Table 4). Staff working in a tighter team structure reported greater team culture $(\beta=0.82 ; 95 \%$ confidence interval [CI], 0.46-1.17; $P<.001)$. Clinicians working in teamlets ( $\beta=1.36$; 95\% CI, $0.55-2.16 ; P<.001)$, but not those working in teams $(\beta=0.30 ; 95 \% \mathrm{CI}$, -0.39 to $0.99 ; P=.40$ ), reported greater team culture than clinicians not working in teams (results not shown in tables).

In multivariate GEE models, more clinician exhaustion was associated with a larger number of half days worked, being in transition to an EHR, and being a resident (Table 3; Models 2 to 4). Across all models, being in a tighter team structure was associated with less exhaustion. Team culture was independently associated with less exhaustion, and adding team culture to model 3 decreased the magnitude of the association of team structure and exhaustion. Team structure and team culture interacted to predict exhaustion, such that among clinicians reporting low team culture, team structure seemed to have little effect on exhaustion, whereas among clinicians reporting high team culture, tighter team structure was associated with less exhaustion (see Table 3, model 4; Figure 1). Clinicians in the tightest team structure (teamlets) and who reported high team culture (using a median split) had exhaustion scores that were $>1.5$ points lower than clinicians not working in teams who reported high team culture, an effect size of $>1$. After removing residents from the regression models, we found a virtually identical pattern of results for the association between team culture and structure and burnout among attending physicians and nonphysician clinicians (data not shown).

In multivariate analysis staff exhaustion was associated with greater tenure and with being in transition to an EHR (Table 3). As was found for clinicians, greater team culture was associated with less exhaustion among staff. However, unlike for clinicians, team structure failed to predict exhaustion among staff, either alone or as part of an interaction term.

\section{Discussion}

Burnout in primary care threatens the engagement of team members and the quality of patient care. We found that perceptions of a better team culture were significantly associated with less clinician exhaustion. A tight team structure seems to have added benefit for the outcome of clinician exhaustion, but only when clinicians perceived an underlying positive sense of team culture. For staff, team culture but not team structure was associated with staff exhaustion.

These findings suggest that fostering a team culture may be an important strategy to protect against burnout in primary care. Prior studies have identified problematic personalities and hierarchy as challenges to effective teamwork. ${ }^{28}$ Health care lags behind many other sectors in institutionalizing training to promote team culture. Examples of training approaches systematically adopted in other settings include crew resource management by the aviation industry and team dimensional training by the US military. ${ }^{30}$ In our own work coaching primary care practices to improve, we have found that one of the basic tasks is facilitating a culture of teamwork through activities such as establishing ground rules, empowering staff to take on new roles, and inverting hierarchical relationships in meeting structures and processes.

Creating structures in which clinicians work consistently with the same medical assistant in a teamlet model, the tightest of team structures, may also reduce clinician exhaustion. However, our results also sound a cautionary note about placing staff in teams without efforts to improve team culture. In practices without a team culture, team structure alone may be ineffective in reducing exhaustion. Particularly for staff, exhaustion did not seem to be directly related to team structure but was associated with team culture. The finding that culture trumps structure for staff is consistent with our experience that when members of a team do not get along or communicate well, team structure alone does not improve the quality of work life. Comments written in response to open-ended questions on the survey support this interpretation, with some staff articulating apprehensions about 


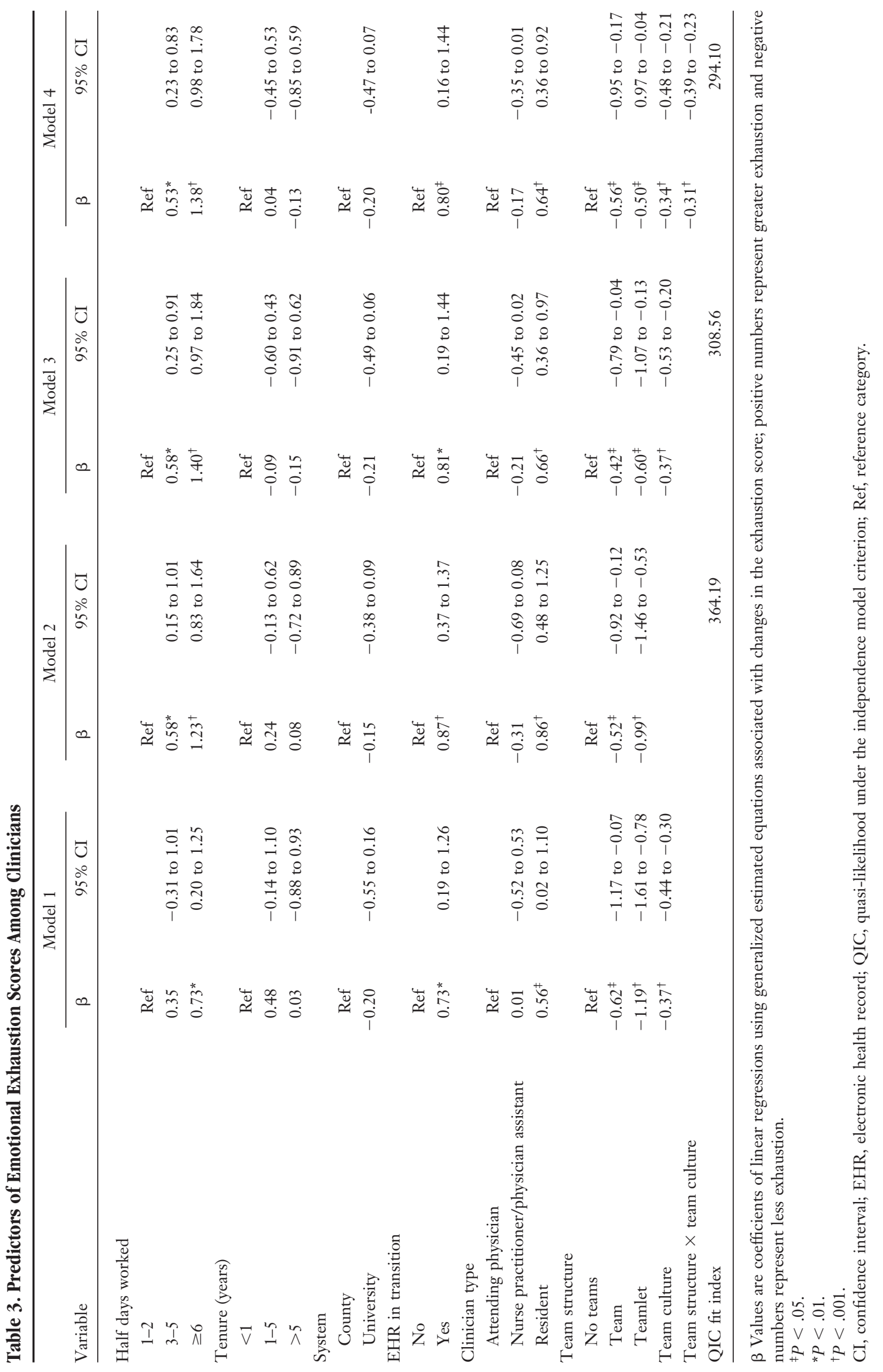




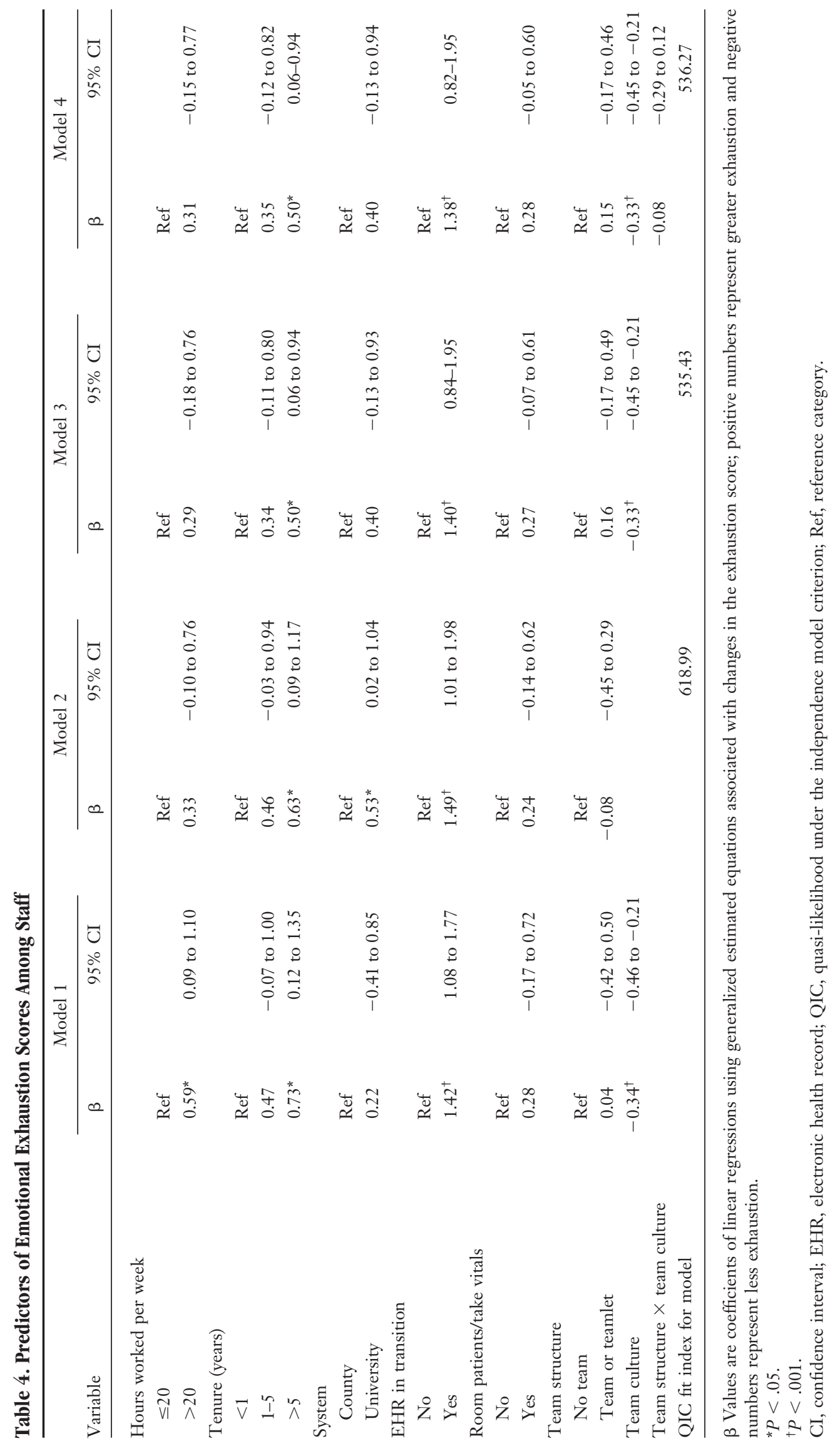


Figure 1. Interaction between team structure and team culture on exhaustion for clinicians (adjusted for covariates). A median split is used to define low versus high team culture.

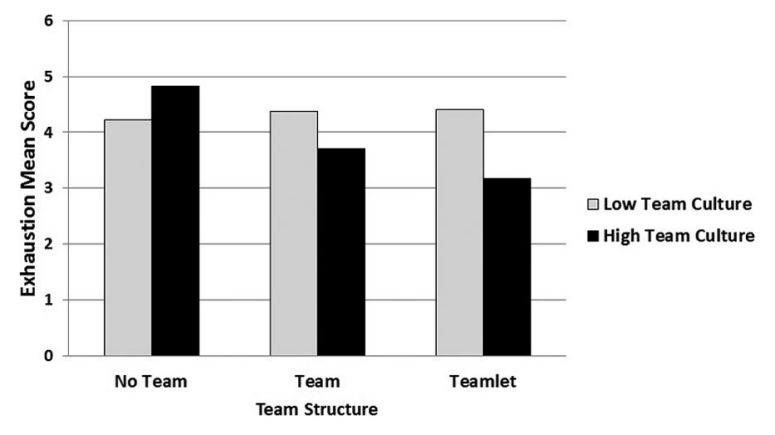

working in tighter team structures if clinic leadership does not set and enforce expectations for respectful communication and personal responsibilities, both of which are key elements of team culture. The divergence in findings for team structure between clinicians and staff may reflect differences in role authority, with clinicians experiencing a tighter team structure as an opportunity to delegate responsibilities and prescribe workflow tasks to medical assistants, and medical assistants finding themselves in a subordinate position irrespective of team structures. ${ }^{33,34}$

The level of exhaustion measured in this study population is troublingly high but similar to that found in the literature. More than half of nonresident clinicians $(55 \%)$ reported high exhaustion, which is comparable to the $50 \%$ reported among a national sample of family physicians and general internists. ${ }^{2}$ Among residents the proportion reporting high exhaustion (69\%) was greater than the level found in several other studies. ${ }^{13,35}$ The proportion of staff reporting high exhaustion (43\%) was greater than the $33 \%$ found in a previous study. ${ }^{1}$ Although not one of our primary research questions, our study detected that transitioning to a new EHR is a stressful experience for clinicians and staff alike.

The types of transformed practice models that are commonly referred to as patient-centered medical homes may change the structure and culture of primary care practice in a way that either enhances or worsens work life experiences. An initial attempt to implement a patient-centered medical home model at group health cooperative was associated with increased clinician fatigue and dissatisfaction; a second attempt that took into account quality of work life demonstrated a significant reduction in clinician and staff exhaustion. ${ }^{1}$ A study using crosssectional methods found that patient-centered medical home attributes were associated with lower morale at a group of safety net clinics, ${ }^{36}$ although there is evidence that improvements in quality and care delivery at safety net clinics are associated with higher morale and lower burnout when there is adequate staffing, fair distribution of responsibility, and training infrastructure. ${ }^{37}$ Keeping a focus on team culture could enhance the effects of practice transformation on work life experiences.

Our study has several limitations. This crosssectional survey cannot examine causal or longitudinal relationships. Data were self-reported. While response rates were comparable to or higher than reported response rates for other surveys of clinicians, ${ }^{38}$ nonresponders may have differed from participants in the survey. Residents and clinicians at teaching clinics and staff at nonteaching clinics were less likely to respond to the survey than their counterparts, which may have influenced the results. Four of the 16 practices included in this sample were teaching clinics, which may also limit generalizability. However, the findings were robust even when residents were excluded. Surveys were conducted in 2 organized health systems with employed physicians, and findings may not be generalizable to other settings and populations. However, the majority of primary care physicians in the United States are now practicing under employed arrangements. ${ }^{39}$ We selected one aspect of team structure-the arrangement of clinicians and clinical assistants-but there are undoubtedly additional structural aspects that are important for effective functioning of teams. In addition, work life factors other than the ones measured in our study may contribute to the experience of exhaustion.

\section{Conclusion}

Our findings suggest that a strong team culture may protect against exhaustion for both staff and clinicians in primary care. Tight team structures such as the teamlet model may help to promote team culture, in particular among clinicians. However, in the absence of a strong team culture, tight team structures may not protect against exhaustion. In addition to advancing the patient-centered triple aims of better care, better health, and more affordable costs, the movement to transform primary care 
may rightly be considered to have quadruple aims, with the fourth aim being to make the practice of primary care a joyful and sustainable job for clinicians and staff. Our findings suggest that to achieve these aims, primary care transformation will need to address not only the structure of team-based care but also infuse these structures with a spirit of team culture.

This research is the result of close partnership with the leadership and staff of 16 primary care clinics across San Francisco. Without the wisdom, expertise, and candid feedback of their clinic leadership, clinicians, and front-line staff, this survey would not have been possible. The study team thanks the San Francisco Department of Public Health and the University of California San Francisco Medical Center for their support of this project in conjunction with primary care reforms undertaken for the Centers for Medicare and Medicaid Services Incentive Program for these health systems under the Section 1115 California Medicaid Waiver.

\section{References}

1. Reid RJ, Fishman PA,Yu O, et al. Am J Manag Care 2009;15:e71-87.

2. Shanafelt TD, Boone S, Tan L, et al. Burnout and satisfaction with work-life balance among US physicians relative to the general US population. Arch Intern Med 2012;20:1-9.

3. Maslach C, Schaufeli WB, Leiter M. Job burnout. Annu Rev Psychol 2001;52:397-422.

4. Biggs WS, Bieck AD, Pugno PA, Crosley PW. Results of the 2011 National Resident Matching Program: family medicine. Fam Med 2011;43:619-24.

5. Zerehi MR. Creating a new national workforce for internal medicine. A position paper of the American College of Physicians. 2006. Philadelphia: American College of Physicians. Available from: http://www. acponline.org/advocacy/where_we_stand/policy/im_ workforce.pdf/. Accessed October 3, 2012.

6. Compton MT, Frank E, Elon L, Carrera J. Changes in U.S. medical students' specialty interests over the course of medical school. J Gen Intern Med 2008; 23:1095-100.

7. Hauer KE, Durning SJ, Kernan WN, et al. Factors associated with medical students' career choices regarding internal medicine. JAMA 2008;300: 1154-64.

8. Bodenheimer T, Pham HH. Primary care: current problems and proposed solutions. Health Aff (Millwood) 2010;29:799-805.

9. Jones PE. Physician assistant education in the United States. Acad Med 2007;82:882-7.

10. Landon BE, Reschovsky JK, Pham HH, Blumental, D. Leaving medicine: the consequences of physician dissatisfaction. Med Care 2006;44:234-42.

11. Linzer M, Manwell LB, Williams ES, et al. Working conditions in primary care: physician reactions and care quality. Ann Intern Med 2009;151:28-36.

12. Shanafelt TD, Balch CM, Bechamps G, et al. Burnout and medical errors among American surgeons. Ann Surg 2010;251:995-1000.

13. West CP, Huschka MM, Novotny PJ, et al. Association of perceived medical errors with resident distress and empathy: a prospective longitudinal study. JAMA 2006;296:1071-8.

14. Jones JW, Barge BN, Steffy BD, Fay LM, Kunz LK, Weubker LJ. Stress and medical malpractice: organizational risk assessment and intervention. J Appl Psych 1988;73:727-35.

15. DeVoe J, Fryer GE, Hawgrawes JL, Phillips RL, Green LA. Does career dissatisfaction affect the ability of family physicians to deliver high quality patients care? J Fam Pract 2002;51:223-8.

16. Firth-Cozens J, Greenhalgh J. Doctors' perceptions of the links between stress and lowered clinical care. Soc Sci Med 1997;44:1017-22.

17. Shanafelt TD, Bradley KA, Wipf JE, Back AL. Burnout and self-reported patient care in an internal medicine residency program. Ann Intern Med 2002;136: $358-67$.

18. Halbesleben JRB, Rathert C. Linking physician burnout and patient outcomes: exploring the dyadic relationship between physicians and patients. Health Care Manage Rev 2008;33:29-39.

19. DiMatteo MR, Sherbourne CD, Hays, RD, et al. Physicians' characteristics influence patients' adherence to medical treatment: results from the Medical Outcomes Study. Health Psychol 1993;12:93-102.

20. Haas JS, Cook EF, Puopolo AL, Burstin HR, Cleary $\mathrm{PD}$, Brennan TA. Is the professional satisfaction of general internists associated with patient satisfaction? J Gen Intern Med 2000;15:122-8.

21. Wallace JE, Lemaire JB, Ghali WA. Physician wellness: a missing quality indicator. Lancet 2009;374: 1714-21.

22. Ghorob A, Bodenheimer T. Sharing the care to improve access to primary care. N Engl J Med 2012; 366:1955-7.

23. Bodenheimer T, Laing BY. The teamlet model of primary care. Ann Fam Med 2007;5:457-61.

24. Sinsky CA, Willard-Grace R, Schutzbank AM, Sinsky TA, Margolius D, Bodenheimer T. In search of joy in practice: a report of 23 high-functioning primary care practices. Ann Fam Med 2013;11:272-8.

25. Crosson JC, Etz RS, Wu S, Straus SG, Eisenman D, Bell DS. Meaningful use of electronic prescribing in 5 exemplar primary care practices. Ann Fam Med 2011;9:392-7.

26. Grumbach K, Bodenheimer T. Can health care teams improve primary care practice? JAMA 2004; 291:1246-51.

27. Hackman JR. Leading teams: setting the stage for great performances. Boston: Harvard Business School Press; 2002. 
28. Valentine MA, Nembhard IM, Edmondson AC. Measuring teamwork in health care settings: a review of survey instruments. Working paper 11-116. September 13, 2011. Boston: Harvard Business School. Available from: http://www.insyght.com.au/wp-content/ uploads/protected/Measuring-Teamwork-in-HealthCare-Settings.pdf. Accessed January 12, 2014.

29. Goh TT, Eccles MP, Steen N. Factors predicting team climate, and its relationship with quality of care in general practice. BMC Health Serv Res 2009;9: 1-11.

30. Jaén CR, Crabtree BF, Palmer RF, et al. Methods for evaluating practice change toward a patient-centered medical home. Ann Fam Med 2010;8(Suppl): S9-20.

31. Maslach C, Jackson SE, Leiter MP, Schaufeli WB, Schwab RL. Maslach burnout inventory manual. 3rd ed. Menlo Park, CA: Mind Garden; 1986.

32. Baker DP, Gustafson S, Beaubien J, Salas E, Barach P. Medical teamwork and patient safety: the evidence-based relation. Literature review. July 2005. AHRQ Publication No. 05-0053. Rockville, MD: Agency for Healthcare Research and Quality. Available from: http://www.ahrq.gov/qual/medteam/. Accessed January 2, 2013.

33. Lingard L, Vanstone M, Durrant M, et al. Conflicting messages: examining the dynamics of leadership on interprofessional teams. Acad Med 2012;87: 1762-7.

34. Thylefors I. All professionals are equal but some professionals are more equal than others? Dominance, status, and efficiency in Swedish interprofessional teams. Scand J Caring Sci 2012;26: 505-12.

35. Goiten L, Shanafelt TD, Wipf JE, Slatore CG, Back AL. The effects of work-hour limitations on resident well-being, patient care, and education in an internal medicine residency program. Arch Intern Med 2005; 165:2601-6.

36. Lewis SE, Nocon RS, Tang H, et al. Patientcentered medical home characteristics and staff morale in safety net clinics. Arch Intern Med 2012; 172:23-30.

37. Graber JE, Huang ES, Drum ML, et al. Predicting changes in staff morale and burnout at community health centers participating in the health disparities collaboratives. Health Serv Res 2008;43:1403-23.

38. Asch DA, Jedriewski MK, Christakis NA. Response rate to mail surveys published in medical journals. J Clin Epidemiol 1997;50:1129-36.

39. Kocher R, Sahni NR. Rethinking health care labor. N Engl J Med 2011;364:1790-3. 